\title{
Volar Locking Plate for Distal Radius Fractures: Functional Outcomes and Complication Rates with a Minimum of One Year Follow-Up
}

\author{
Kastanis G ${ }^{1}$, Pantouvaki ${ }^{2}$, Kapsetakis $P^{1}$, Spyrantis $M^{3}$, Magarakis $\mathbf{G}^{1}$, Christoforidis $\mathrm{C}^{1}$, Stavrakakis $\mathrm{I}^{1}$ \\ ${ }^{1}$ Department of Orthopaedic, General Hospital of Heraklion -Venizeleio, Crete, Greece \\ ${ }^{2}$ Department of Physiotherapy, General Hospital of Heraklion -Venizeleio, Crete, Greece \\ ${ }^{3}$ Department of Orthopaedic and Traumatology, University Hospital of Heraklion, Crete, Greece
}

*Corresponding Author: Grigorios Kastanis; kastanisg@gmail.com

Received 22 April 2021;

Accepted 16 May 2021;

Published 28 May 2021

\begin{abstract}
Distal radius fractures (DRF) are the most common type of fractures of the upper extremities with an incidence of $44 \%$ of all types of forearm and hand fractures. In unstable DRF, the aim of surgical treatment is to restore a functional wrist. Volar locking plate is supported in literature as a promising surgical method in treatment of these fractures. The aim of this study is to analyze the type and complication rate with applied volar locking plate, the percentage of revision surgery and the functional outcomes in a minimum of one year follow up. Material \&Methods: 104 fractures in 98 patients with a mean range of 48,5 years-old age underwent for unstable distal radius fractures with volar locking plate. The main cause was simple fall to an outstretched hand. In ten cases the fracture was open while in 28 cases the DRF was accompanied with ulnar styloid. All fractures classified by AO/OTA in A2-3 27 cases, B1-3 in 45 and C1-3 in 32 cases. The majority of patients were operated within 48-72 hours after injury. In all cases an extended flexor carpi radialis approach was performed and a volar locking plate was applied in all DRF's. In sixteen cases with base of ulnar styloid fractures, low profile locking plates were applied, while in the rest of patients Kirschner wires were used. Postoperatively all patients followed a standard protocol rehabilitation program with passive and active motion of fingers and wrist. Results: Patients were evaluated according to complication (type and rate), time to fracture union, range of motion, Visual analogue pain scale, Quick Dash Score and patients-rated wrist evaluation score. Complications were distinguished in major and minor. Patients under 60 years-old with type fracture A2-3 and B1-3 showed better range of motion and grip strength than patients over 65 years old. In cases with type fractures C1-3 and age over 65 years old, ROM and grip strength decreased compared with the unilateral side. The percentage of complication and reoperation appeared more increased in type C1-3 related to the other two types of fractures. Finally the mean Quick DASH was $11,1 \pm 12,8$, RPWE was $9.8 \pm 13,6$ and the range of motion was in extension $75,2 \pm 7,3$, in flexion $74 \pm 8,9$, in pronation $85,6 \pm 1,9$, in supination $88,5 \pm 2,4$ in radial deviation $9,8 \pm 1,2$ and in ulnar deviation $41,1 \pm 4,6$ and grip strength was an average of $84,7 \%$ of uninjured hand. Conclusion: Unstable fractures required operative treatment with volar locking plate to be the gold standard in recently years. Unfortunately VPL presents postoperative complications related with plate and screw position with comminuted fracture or soft tissue damage which cannot be ignored, and for these reasons may be inadequate for all types of distal radius fractures.
\end{abstract}

Keywords: Distal radius fracture, Volar locking plate, Complications, Functional outcome

\section{Introduction}

Distal radius fractures (DRF) are the most common type of fractures of the upper extremities treated in emergency department. Fanuele et al(2009) reported that incidence of DRF is 125 in 100.000, while Brogren et al (2007) presented that this type of fractures rises to as high as 119 in 10.000 in women of 80 years-old and elder ${ }^{[1,2]}$. The incidence of it accounts to $44 \%$ of all types of forearm and hand fractures and $20 \%$ of all fractures of skeletal body ${ }^{[3]}$. Huetteman et al (2018) suggested that the average cost of care for a distal radius fracture patient was up to eight thousand dollars in the United States during 2009-2015 ${ }^{[4]}$.

Distribution of these fractures depending on age is bimodal. In geriatric patients especially women over 6o years old have a higher lifetime risk of $15 \%$ more than men in similar age and often associated with poor bone quality and osteoporosis, and occur after a low-energy accident as simple fall from standing height ${ }^{[5]}$. On the contrary, in young persons who have normal bone quality the fracture is a result from high energy traumas such as motor accident, fall from a height, and industrial impaction injuries and suffer from comminuted or terribly displacement fractures ${ }^{[6,7]}$. 
Conservative treatment after closed reduction is the gold standard for stable distal radius fracture, involving wrist immobilization in a plaster of paris cast for 4-6 weeks, following rehabilitation program. Lafontaine et al(1989) criteria(age $>60$ years, dorsal angulations $>20^{\circ}$, dorsal comminution, fracture extension into the radiocarpal joint with intraarticular step-off more than $2 \mathrm{~mm}$, and associated ulnar fracture) characterize unstable DRF fracture or suggest the risk factor of unstable fracture besides their initial sufficient reduction ${ }^{[8]}$. The aim of surgical treatment is to restore radial bone articular surface, alignment of the wrist and to avoid osteoarthritis and functional dysfunction of the wrist ${ }^{[9]}$. Historically from the first surgical method with cast and percutaneous Kirchner wire, various surgical techniques have been presented as screw fixation, external fixation, internal fixation with plates ${ }^{[10]}$. From 2000 when volar locking plate was available for use in DRF's until today, this procedure was the most popular. The advantage of this low profile locking plate is to achieve anatomical reduction of comminuted or osteoporotic DRF and to avoid compression and irritation of median nerve and flexor tendons, leading to better clinical outcomes and functional recovery. For all these reasons an increased use of these implants have been developed in hand surgery ${ }^{[11]}$. International literature presents studies which report postoperative complication of volar locking plate (VPL) fixation of distal radius fracture with statistics that support a large discrepancy. McKay et al(2001) reported that incidence of complication of VPL ranges from $6 \%-80 \%$, while Thorninger et al(2017) in a follow-up of 3,2 years presented a percentage which varied from $3 \%$ to $36 \%{ }^{[12,13]}$. These complications rate leads to secondary revision surgery which varied from $2 \%$ to $34 \%$ with an increased total cost of treatment [14,15].

The purpose of this study is to analyze postoperative complication type and rate of volar locking plate fixation for distal radius fracture in our institution, the percentage of revision surgery, and to report the functional outcomes of our cases in a minimum of one year follow-up.

\section{Material \& Method}

From $1^{\text {st }}$ July 2017 to 31 December 2019 all patients who treated for distal radius fracture at the Orthopaedic department of General Hospital of Heraklion-"Venizeleio" with a volar locking plate and met the criteria have been introduced in this study. Inclusion criteria were: I age $>20$ years old, II surgical procedure with open reduction and fixation and only volar locking plate used, III followup interval at least 2 years, IV unstable distal radius fractures, V polytrauma. Exclusion criteria were: I age younger than 18 years old, II patients who received any surgical treatment from another hospital, III corrective osteotomies, IV distal radius fracture with prior fixation with external fixation. The Institutional Ethical Committee approved this study.

Indications for surgical treatment were a displaced distal radius fracture with an intra-articular step of more than $2 \mathrm{~mm}$, radial shortening more than $2 \mathrm{~mm}$, dorsal tilt more than 15 degree, incongruence in distal radio-ulnar joint in preoperative $\mathrm{x}$-rays or $\mathrm{ct} / \mathrm{scan}$ and bilateral DRF. Ninety eight patients with 104 unstable fracture of DRF and an average age of 48,5 years old (range from 26 to 79) were stabilized by palmar locking plate due to unstable DRF. The right hand was involved in 58 and the left in 34 cases, while six cases appeared with bilateral fracture. The majority of patients presented one or more comorbidities in their clinical history including diabetes mellitus, osteoporosis, hypertension, coronary artery disease, chronic obstructive pulmonary disease
(Table I). The main cause of fracture was simple fall from standing height with an outstretched hand (Table II). In ten cases the fractures were open classified by Gustilo \& Anderson in Grade I (7 cases) and Grade II (3 cases). Fractures were classified using AO/OTA classification system as type 23 A2-3(27 cases 26\%), B1$3(45$ cases $43,3 \%)$ and $\mathrm{C} 1-3(32$ cases $30,7 \%)$ based on preoperative $\mathrm{x}$-Rays or ct/scan imaging. In 28 cases $(26,9 \%)$ the DRF was accompanied with distal ulnar fractures (19 cases localized in the tip and the rest in the base of styloid process). Seventy four patients were operated in a mean time of 48-72 hours after injury while the rest of patients who were diagnosed with displacement of the fracture from the prior closed reduction and cast application during follow up (x-rays) were operated in a mean time of 13 days.

Table I. Demographic characteristics of patients

\begin{tabular}{|l|l|}
\hline Gender (male/female) & $32 / 66(32,7 \% / 67,3 \%)$ \\
\hline Mean Age & $46,5(26-79)$ \\
\hline Hand Involved (Right/Left) & $58 / 34(63,1 \% / 36,9 \%)$ \\
\hline Hand Dominance (Right/Left) & $76 / 22(77,6 \% / 22,4 \%)$ \\
\hline Open Injuries & $10(5,7 \%)$ \\
\hline Bilateral & $6(3,25 \%)$ \\
\hline Ulnar styloid Fracture & $28(26,9 \%)$ \\
\hline Polytrauma & $14(13,4 \%)$ \\
\hline Comorbidities & \\
\hline Diabetes Mellitus & $22(22,4 \%)$ \\
\hline Hypertension & $30(30,6 \%)$ \\
\hline Osteoporosis & $37(37,8 \%)$ \\
\hline Coronary Artery Disease & $11(11,2 \%)$ \\
\hline Chronic obstructive pulmonary disease & $12(12,2 \%)$ \\
\hline
\end{tabular}

Table II. Cause of Distal Radius Fracture

\begin{tabular}{|l|l|}
\hline Cause & Patients \% \\
\hline Fall from standing height & $60(57,7 \%)$ \\
\hline Sport Injuries & $13(12,5 \%)$ \\
\hline Vehicle Accident & $25(24 \%)$ \\
\hline Industrial injuries & $6(5,8 \%)$ \\
\hline
\end{tabular}

\section{Surgical Procedure}

All patients were operated with regional or general anesthesia (depended ASA score), in supine position with arm tourniquet and fluoroscopic control and all operations were performed by author. Extended flexor carpi radialis approach described by Orbay et al (2001) was performed ${ }^{[16]}$. Flexor carpi radialis tendon was released from sheath, retracted ulnar protected median nerve. Forearm fascia was dissected and distal and lateral borders of quadrates a pronator muscle was mobilized with an L-shaped incision. The brachioradialis tendon was released from the radius bone. The radius fracture was reduced and stabilized temporarily with Kirschner wires while the quality of reduction was controlled by fluoroscopy. The locking plate was positioned on the volar surface of the radius distal to watershed line (in majority of cases) and initial stabilization of the plate was performed with the bicortical screw. A new control of the correct position of the plate was executed by fluoroscopy and the stabilization was continued with the rest locking screws. In all cases the locking screws were $2 \mathrm{~mm}$ shorter than prior measurement to avoid protrusion in extensor tendons. A final control with $\mathrm{C}$-arm intensifier was performed to check the final osteosynthesis (position of the plate, reduction of the fracture and the route of screws in order to not penetrate the radiocarpal joint). Range of motion, fracture stability and stability 
of distal radioulnar joint were examined before skin closure. The brachioradialis and quadrates pronator muscles were sutured back in initial anatomical position to cover the implant and to avoid irritation from the flexor tendons. In distal ulnar fracture an ulnar approach was performed and the fracture was stabilized with low profile locking plates (16 cases $(57,1 \%))$ or Kirschner wires (12 cases $(42,9 \%)$.(Fig 1(a),1(b),1(c) In 18 cases a distal radio-ulnar joint dysfunction was diagnosed after DRF fixation and Kirschner wire was applied for 4 weeks. In 8 cases a bone allograft was placed.

Postoperatively the volar cast was applied for two or four weeks, in order to assist soft tissue healing. The stitches were removed in two weeks, while the cast was remained, depending on the comminution of the fracture and the quality of the osteosynthesis, for a varying period of two to four weeks.

All patients underwent a standard rehabilitation protocol program from the first postoperative day starting from adjacent joints. Active exercises were given for shoulder and elbow joints. Active-assisted exercises were performed in free finger joints while supervised physiotherapy treatment initiated, after immobilization phase. Continuous passive movement and active assisted exercises in wrist and finger joints were performed initially to restore joint range of motion. Patients were trained to follow a home based daily exercise program to increase range of movement and enhance muscle strength and grip strength in a later phase.

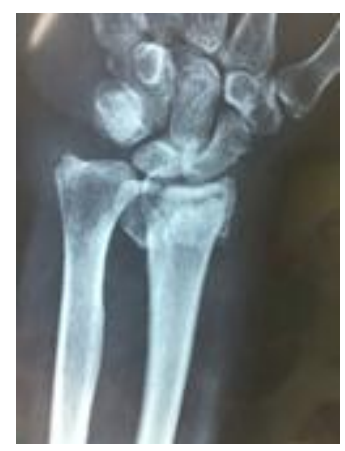

(a)

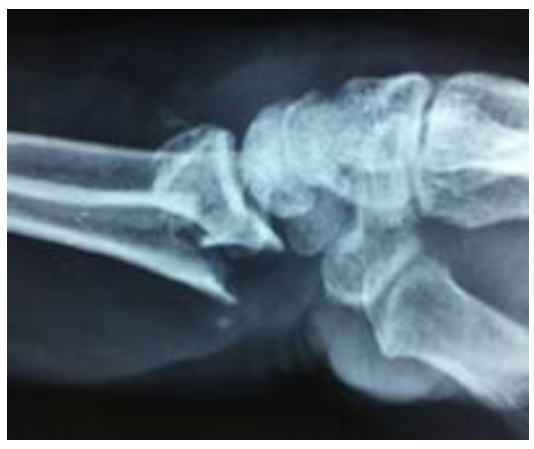

(b)

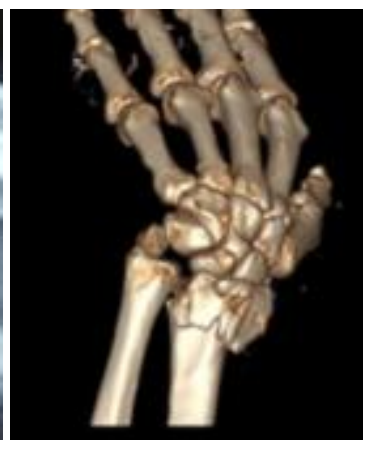

(c)

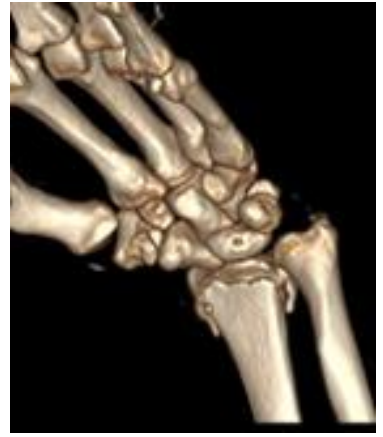

(d)

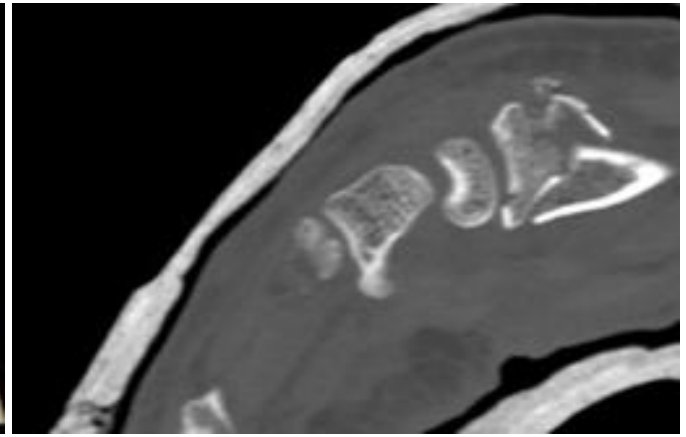

(e)

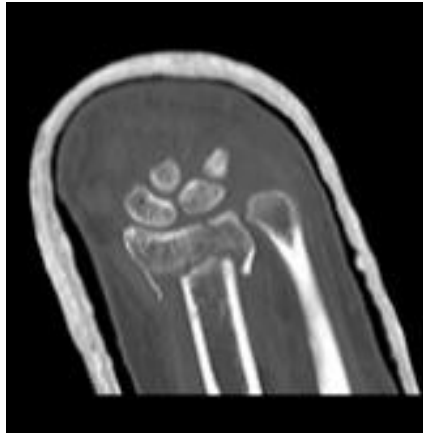

(f)

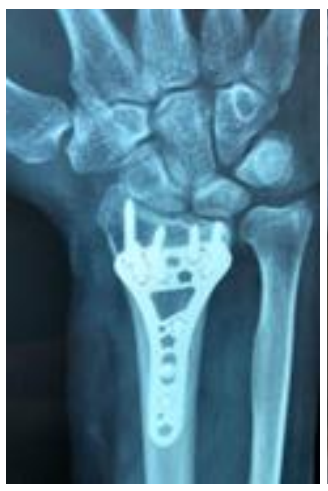

(g)

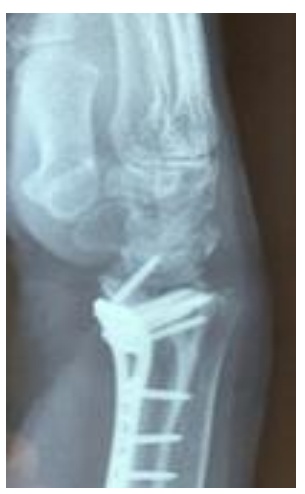

(h)

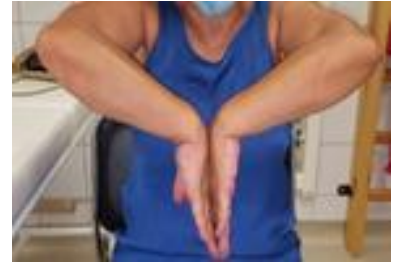

(J)

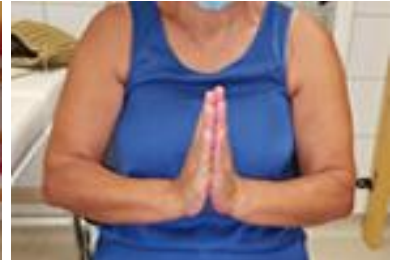

(K)

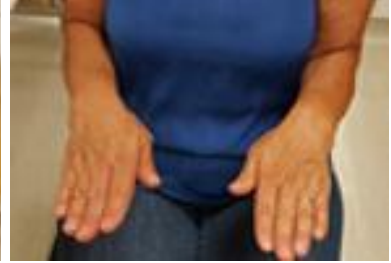

(1)

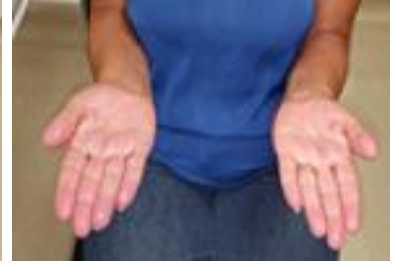

(m)

Figures1: A 58 years-old female with type $\mathrm{C} 1$ fracture of left distal radius. Preoperative x-Rays (AP(a), lateral(b)) and ct/scan(c,d,e,f). At one 18 months $x$-Rays

(AP (g), lateral (h)) and range of motion $(\mathbf{j}, \mathbf{k}, \mathbf{I}, \mathrm{m})$ 


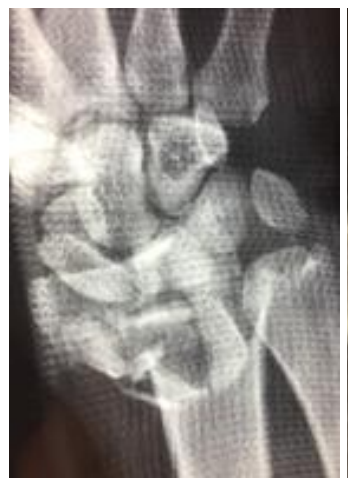

(a)

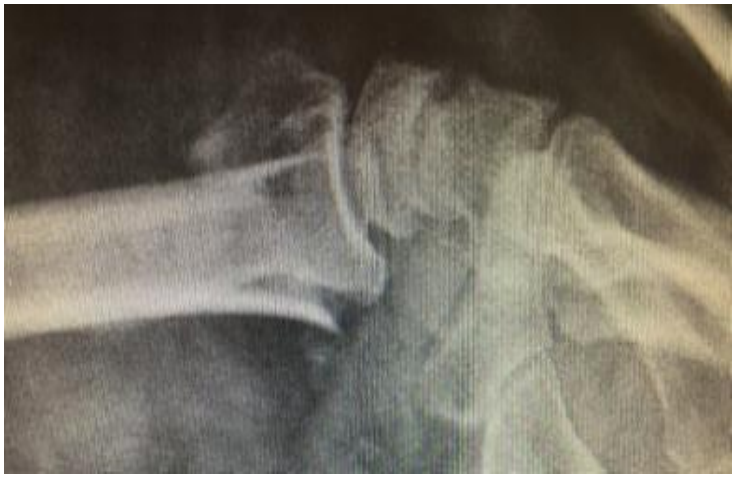

(b)

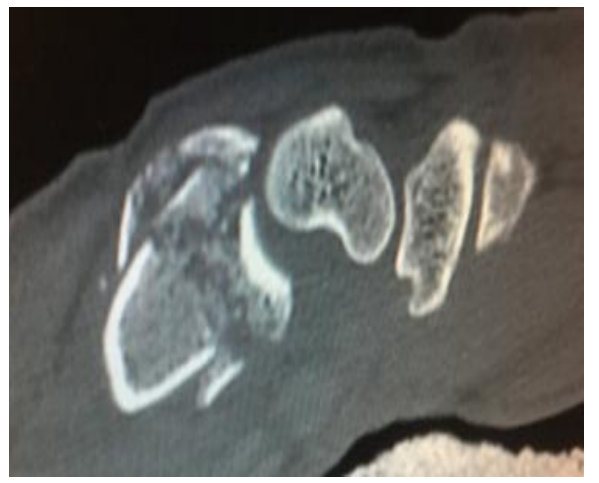

(c)

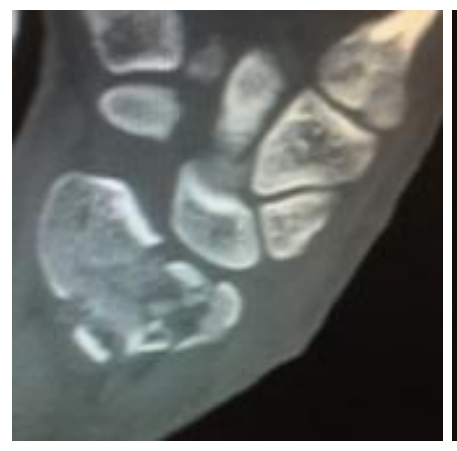

(d)

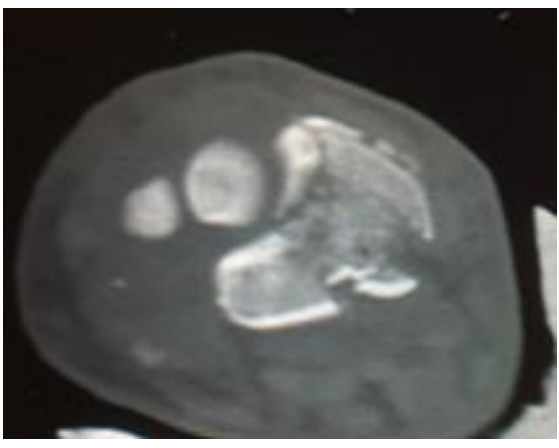

(e)

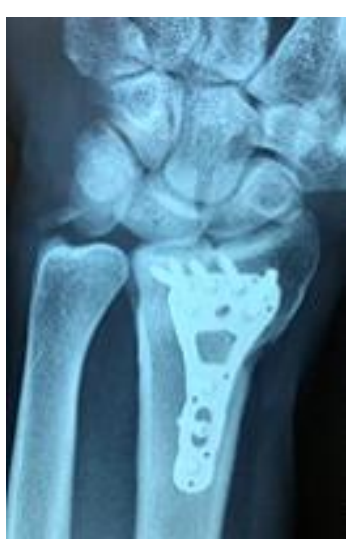

(f)

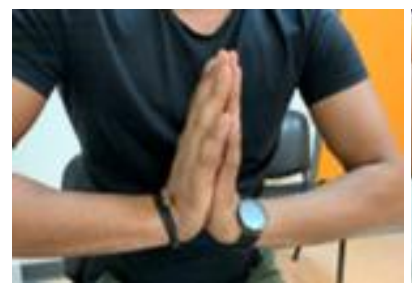

(h)

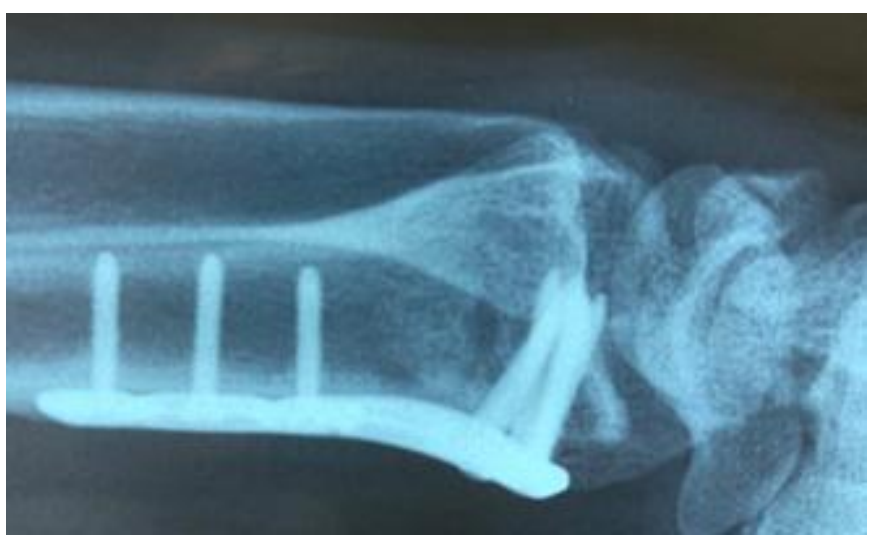

(g)

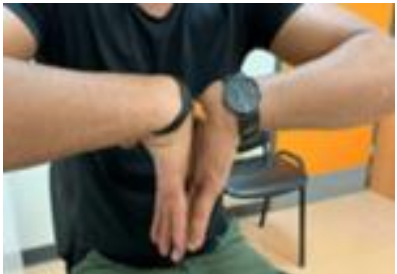

(j)

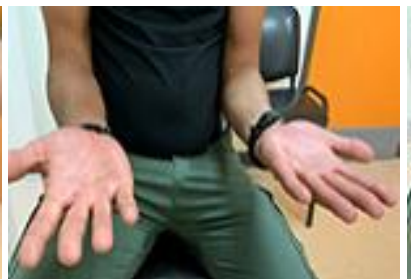

(k)

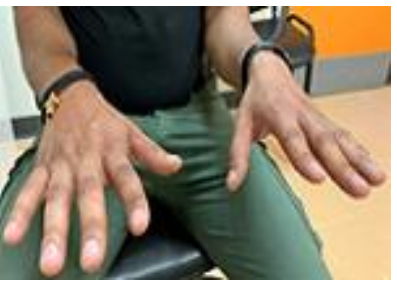

(1)

Figure 2: A 26 years-old male with type $\mathrm{C} 1$ fracture of left distal radius. Preoperative $x$-Rays (AP(a), lateral(b)) and ct/scan(c, d, e,). At one 24 months $x$-Rays

(AP (f), lateral (g)) and range of motion $(h, j, k, I$,)

\section{Results}

The mean follow-up is about 18,5 months (range from 14 months to 32 months ). None of patients missed the last re-examination. Results were evaluated according to complications and fracture union determined by follow-up x-Rays, the range of motion measurements, and completion of Visual Analogue pain Scale, Quick Dash Score and Patient-Rated Wrist Evaluation score(PRWE). All cases were assessed in two weeks and in $1,3,6,12$ months post surgically.
Complications were distinguished in two categories (majorminor) and were related with classifications of fractures (Table III). Major complications were classified as follows: Tendons (flexor, extensor) irritation or rupture, painful intraarticular screw, malunion or loss of fixation, reoperation, and radial artery injuries necessary restoration. Minor complications were described as follows: Carpal tunnel syndrome (overtime four months post surgery), transient hyposensitivity, delayed union (incomplete radiographically appearance of bone callus), complex regional pain syndrome. Intraarticular screw penetration was present as the most major complication especially in type $\mathrm{C} 1-3$ fractures in percentage 
of $12,5 \%$ and in type B1-3 with an incidence of 2,2\%. All cases were re-operated after healing of the fractures with a mean time of 8-10 weeks postoperatively and with the patient recovering functional activity of the wrist. Four cases developed tendon irritations (one extensor pollicis longus, one flexor pollicis longus and two flexor carpi radialis) from the implant or screw. In these cases post operative lateral $\mathrm{x}$-rays were done to verify plate position and according to Soong et al there were type II in two cases $(\mathrm{C} 3)$ and type $\mathrm{I}$ in one case ${ }^{[17]}$. Extensor pollicis longus was irritated from a screw and in this case the fracture was type B3. The implant was removed at a mean time of 8,2 weeks(8-10 week). There was no rupture of tendon. Three cases were diagnosed intraoperatively with radial artery rupture. Two of the cases with radial artery damage were restored (type C1-3) and one was ligated (B-3) because the patient had severe medical history( ASA III) ${ }^{[18]}$. Five cases developed malunion with an incidence of $2,2 \%$ in type B3 and $12,5 \%$ in type C1-3. In type C3 (3 cases 9,3\%) fractures presented with an increased percentage of malunion while in type $\mathrm{C} 2$ (one cases 3,2\%) and in type B1-2(one case).

Referring to minor complications the carpal tunnel syndrome (CTS) was more common in all types of fracture with an increased percentage (12,5\%) in type C1-3, following the transient hyposensitivity of the thumb(two cases). Five cases with CTS were treated with open release but the implant was not removed. In the other two cases the symptoms were ameliorated with physiotherapy treatment. Infection was present in two cases in which after administration of cephalosporin the symptoms were disappeared. Finally two cases with complex regional pain syndrome were treated with physiotherapy, non-steroidal anti-inflammatory drugs and vitamin $\mathrm{E}$.

Radiography examination (posteroanterior and lateral view) were taken after surgery, in 1, 3,6,12 months and in final assessment. On x-rays we examinated the position of the plate position according to Soong, the union of the fractures, radiographic parameters (dorsal angulation, radial inclination ulnar variance) ${ }^{[17]}$. Among plate position 79 cases $(76 \%)$ were Soong type $\mathrm{O}, 17(16,3 \%)$ were type I and 8 fractures $(7,7 \%)$ were type II. Union was obtained in mean time of 7,3 weeks(range 6-10 weeks). At the final examination the radial inclination was mean $23,4 \pm 4,1$, palmar tilt $2,1 \pm 5,8$ and ulnar variance $1,2 \pm 2,2$. Correlation between radiological parameters and sex or age of patients were not significant, but they might be related with the type of fracture, more increased in type C1-3 fractures in which there were 4 cases with malunion and 2 with lost of reduction.

At final examination mean score of pain was $0,29+1,08$ according to Visual Analogue Scale, mean range of motion was in extension $75,2+7,3$, in flexion $74+8,9$, in pronation $85,6+1,9$, in supination $88,5+2,4$ in radial deviation $9,8+1,2$ and in ulnar deviation $41,1+4,6$. Grip strength was a mean of $84,7 \%$ of the uninjured hand, Quick DASH was $11,1+12,8$, and PRWE was $9,8+13,6$. Analyzing the results it can be concluded that patients under 60 years- old $(63,2 \%)$ with type fracture A2-3 and B1$3(69,2 \%)$ showed better range of motion and grip strength than patients over 65 years old(36,8\%). In our sample of patients (18/32 cases) in which the age is over 65 and fracture type is C1-3, the range of motion and grip strength is decreased compared to the unilateral side. In type C 1-3 fractures major complication rate appeared more frequently $(71,85 \%)$ compared with type B1$3(13,3 \%)$ and A2-3(0\%). Minor complication rate do not show significant differences between all types of fracture. The larger percentage of reoperation is shown in type C1-3 (25\%) with predominance in type $\mathrm{C} 3(15,6 \%)$ while in the type B1-3(4,4\%). Concomitant fracture of tip or base of ulnar styloid do not show any differences regarding final range of motion, pain or grip strength.

Table III. Complication based on AO/OTA

\begin{tabular}{|c|c|c|c|}
\hline Complication & $\begin{array}{c}\mathrm{A} 2-3(27) \\
\%\end{array}$ & $\begin{array}{c}\text { B1-3 (45) } \\
\%\end{array}$ & $\begin{array}{c}\text { C1-3(32) } \\
\%\end{array}$ \\
\hline \multicolumn{4}{|l|}{ Major } \\
\hline Tendon irritation & & $1(2,2 \%)$ & $3(9,3 \%)$ \\
\hline Intra-articular screw & & $1(2,2 \%)$ & $4(12,5 \%)$ \\
\hline Radial artery injuries requiring repair & & $1(2,2 \%)$ & $2(6,25 \%)$ \\
\hline Malunion & & $1(2,2 \%)$ & $4(12,5 \%)$ \\
\hline Lost of reduction & & & $2(6,25 \%)$ \\
\hline Hardware removal-reoperation & & $2(4,4 \%)$ & $8(25 \%)$ \\
\hline \multicolumn{4}{|l|}{ Minor } \\
\hline Carpal Tunnel Syndrome & $1(3,7 \%)$ & $2(4,4 \%)$ & $4(12,5 \%)$ \\
\hline Superficial infection & $1(3,7 \%)$ & & $1(3,1 \%)$ \\
\hline Transient hyposensitivity (Thumb) & 0 & $1(2.2 \%)$ & $1(3,1 \%)$ \\
\hline CRPS & 0 & $1(2,2 \%)$ & $1(3,1 \%)$ \\
\hline
\end{tabular}

\section{Discussion}

Distal radius fracture is the most common injury in emergency department with an incidence of 36.8/10.000 person per year in woman and 9.0/10.000 person per year in men over 35 years old ${ }^{[19]}$. The incidence of DRF is expected to continue rising due to increased average living ${ }^{[20]}$. The aim in therapy of unstable distal radius fracture is to restore stable anatomy of the articular surface area allowing fast recovery, to regain the wrist functionality and to prevent stiffness, secondary displacement of the fracture and to achieve a painless functional wrist.

In literature many therapeutically surgical procedures have been proposed for treatment of unstable DRF. Orbay et al(2001) first proposed the volar locking plate leading to increased percentage of internal fixation with the VPL.16 Initially the same author presented preliminary results of 31 fracture treated with palmar approach and VLP, concluding that "combination of stable internal fixation with preservation of the dorsal soft tissue leads to promptly fracture healing, decreases the need of bone grafting and presents low complication rate from tendon irritation" [21]. The advantage of these plates in relationship with convectional plates was that provides fixation strength, superior stiffness and axial loading strength, avoids extensor tendon irritation(dorsal plates) and finally the plates can be applied along volar cortex of distal radius surface and control dorsally displacement fractures ${ }^{[22,23]}$. 
The rate of complications after volar locking plate in DRF varied in literature from $3 \%-60 \%$ depending on the study design, the participants, sample size, and the follow-up period $[13,14,21,23,25,26]$. Bentohami et al(2014)in a systematic review report that overall complication rate is $16,5 \%$ with the most common type nerve and tendons function and complex regional syndrome, while De George et al(2020) report a complication rate of $31,3 \%$ with the most common complication transient paresthesia, tendon rupture or irritation and symptomatic implant ${ }^{[27,28]}$. Quadlbauer et al (2020) in 230 cases with an average follow-up of 20 months, report an incidence of complication rate $13 \%$ with the most common including Carpal Tunnel Syndrome, intraarticular screw, and CRPS. Intraarticular screws is a complication with a rate of $0,5 \%$ to $1,3 \%$ which leads to loss of reduction or secondary fracture dislocation. Esenwein et al (2013) report that the use of angular stable screws do not preclude any secondary displacement ${ }^{[29]}$. Intra-articular screws penetrate the radiocarpal or distal radioulnar joint (DRUJ) leading to osteoarthritis and malunion. In our study the rate was $5 / 104(4,8 \%)$, in which the screw was in radiocarpal joint in four cases and one in DRUJ. In all cases that screws were removed the symptoms ameliorated with an increased range of motion.

Carpal Tunnel Syndrome (CTS) is a widespread disease which occurs in distal radius fracture. Rate of appearance of CTS after surgical treatment of DRF varied from 7\%-15\% regardless the method $^{[25,30]}$. Alter et al (2019) suggested that the syndrome is not correlated with the implant but to trauma of the nerve during fracture, or fracture's healing with callus formation or malunion. Another explanation has been proposed from Quadlbauer et al(2020) in which the CTS preexisted undiagnosed and asymptomatic and the symptoms aggravated after the fractures or patients gave more attention after the injury ${ }^{[25,31]}$. In our series we have 7 cases with CTS, with 3 patients to be diagnosed before fracture. Five patients underwent open release without implant removal and they had improvement concerning symptoms, while in other two cases the symptoms were ameliorated after physiotherapy.

Tendons (flexor or extensor) irritation or rupture is a common complication after surgical treatment of DRF in which the incidence varied from $0,5 \%-4,7 \%{ }^{[14,23,28]}$. Reports prove that when palmar plate applied over or distal to watershed line in the radius is related with complication of flexors tendon pathology ${ }^{[32]}$. This concept proposed from Cross et al(2008) who report ruptures of flexor pollicis longus and flexor digitorum profundus ${ }^{[33]}$. Imatani et al(2012) in a anatomical study suggest that "medial and lateral bony prominences on the volar radius should be key structures for accurate plate placement to avoid flexor tendon injury" ${ }^{\text {,34] }}$. To avoid these complications Soong et al (2011) proposed a grading system from 0-II (Plates that did not extend volar to this line were recorded as Grade 0, plates volar to the line, but proximal to the volar rim, were recorded as Grade I, and plates directly on or distal to the volar rim were recorded as Grade II) indicate a predisposition for flexor tendon rupture if the plate is applied distal to volar rim of radius ${ }^{[17]}$. To compensate peripheral placement of the plate, Buzzell et al(2008) suggest the requirement of locking screws or pegs to support subchondral bone ${ }^{[37]}$ Drobetz et al (2006) in a biomechanical study suggest that distal screws need to be positioned just beneath the subchondral bone of the radial articular surface, because when screw's length is longer than subchondral bone this leads to double fracture displacement when compared with fixation within subchondral zone ${ }^{[38]}$.

On the contrary, extensor pollicis longus tendon (EPL) was more often suffered from all extensor apparatus of the wrist.
Causes are prominent screw from the radial side of volar plate in the region of Lister's tubercle or management of dorsal comminution ${ }^{[13,28,30]}$. In our study we describe four cases with tendons irritation in which one concerned the EPL and the cause was a prominent screw while in the other three cases the volar plates were applied more distally (Soong I,II). After removing the implant and screw, the symptoms were ameliorated and the patients had an increased range of motion and functionality of the wrist.

Complex regional pain syndrome (CRPS) is accompanied with general injuries of upper extremities. It is associated after DRF with an incidence from $1 \%-6 \%{ }^{[24,29]}$. The pathological mechanism has not been elucidated but Tanl et al(2011) suggest that CRPS is being related to an over excretion of cytokinins, mitochondrial dysfunction in the affected upper extremity, as well as genetic predisposition does exist ${ }^{[35,36]}$. Quadlbauer et al(2020) support that CRPS is a complication, that cannot be influenced by the surgeon. Only two cases from 104 fractures present CRPS in which the symptoms after conservative treatment (physiotherapy, non-steroidal anti-inflammatory drugs and vitamin E) were retreated in a mean period of 7-8 weeks.

$\mathrm{Li}$ and Sirnio support that the bone comminution and soft tissue damage can increase the percentage of complication rate after surgical treatment of DRF ${ }^{[14,39]}$. Gluek et al(2009) in 42 cases with open DRF concluded that larger degree of open fracture increases the percentage of postoperative infection ${ }^{[40]}$. Tsang et $\mathrm{al}(2014)$ present that rate of complication in type $\mathrm{C}$ fracture is $22,2 \%$ while $\mathrm{Li}$ et al $16,4 \%$ and the author suggest that open distal radius fracture type $\mathrm{C}$ must be managed with multiple and thorough debridement's as part of the initial treatment plan to reduce or prevent the complications ${ }^{[14,41]}$. In that study 10 cases $(9.7 \%)$ were open and from them 6 cases were type C fractures, 3 cases type B and one case type A. As far as postoperative infection concerns, we manage one case in type $\mathrm{C}$ and one in type A. Managing type $\mathrm{C}$ fracture especially in type C3 (we have the largest number of complications (8/32) and we present along with Tsang et al about the same complication rate. We agree with $\mathrm{Li}$ et al that precise and meticulous debridement of the open fractures avoids the percentage of postoperative infection.

A main cause that leads to malunion is the loss of reduction of lunate fossa with articular step-off. Berlung et al(2009) suggest that inadequate fixation of the lunate fossa leads to postoperative loss of reduction even if sufficient reduction was obtained ${ }^{[45]}$. Harness et al(2004) report 25 cases with this complication while Li et $\mathrm{al}(2019)$ present 23 cases and suggest that fracture involving lunate fossa are difficult to be reduced from the volar surface of the distal radius and a standard volar plate fixation is insufficient to provide equal fixation and stabilization to both the scaphoid and the lunate fossa ${ }^{[14,44]}$. In the current study we diagnosed 5 cases in 104 fractures $(4,8 \%)$ with the above complication in type C1-3. Benson et al (2006) propose that fragment specific fixation is an alternative method to stabilize the individual intra-articular fracture fragment, while Lee et al (2003) proposed Kirschner wire to stabilize the lunate fossa ${ }^{[42,43]}$.

This study is presented with the following limitations. First, the small number of distal radius fractures (104 fracture) and second the quite short follow-up period (18,5 months). Possibly a larger sample of patients leads to more reliable results over a longer follow-up time regarding complication type and rate. Third, the intra-articular fracture evaluation was executed by radiography presenting less sensitivity than computer tomography which can display an intraarticular step-off or cartilage damage. Four, we cannot quantify patient's factor (smoking, alcohol, diabetes) which can affect the complication rate. Five, we could not evaluate if the 
early or delay time to surgery affects the rate of complication. Finally the posttraumatic degeneration was not detected.

\section{Conclusion}

Distal radius fractures are frequent injuries that occur in emergency department. Unstable fractures require operative treatment in which volar locking plate is the gold standard. Unfortunately VPL presents postoperative complications related with the plate and screw position, with the comminution of the fracture or soft tissue damage which we cannot ignore. Possibly volar locking plate may be inadequate for all distal radius fracture. Good preoperative planning of the fracture and good selection of the implant may decrease the percentage of secondary reoperation.

\section{Conflict of Interest}

The authors declare that have no conflict of interest.

\section{Ethical Approval}

The Institutional Ethical Committee approved this study.

\section{References}

[1] Fanuele J, Koval KJ, Lurie J, Zhou W, Tosteson A, Ring D. Distal radial fracture treatment: what you get may depend on your age and address. J Bone Joint Surg Am. 2009, 91(6): 1313-9, doi:10.2106/JBJS.H.00448.

[2] Brogren E, Petranek M, Atroshi I. Incidence and characteristics of distal radius fractures in a southern Swedish region. BMC Musculoskelet Disord. 2007;31(8): 48, doi:10.1186/1471-2474-8-48.

[3] Chung KC, Spilson SV. The frequency and epidemiology of hand and forearm fractures in the United States. J Hand Surg Am. 2001; 26(5):908-15, doi:10.1053/jhsu.2001.26322.

[4] Huetteman HE, Zhong L, Chung KC. Cost of surgical treatment for distal radius fractures and the implications of episode-based bundled payments. J Hand Surg. 2018; 43(8):720-30, doi:10.1016/j.jhsa.2018.05.007.

[5] Lameijer CM, Ten Duis HJ, Vroling D, Hartlief MT, Moumni M El, Van der Sluis CK. Prevalence of posttraumatic arthritis following distal radius fractures in non-osteoporotic patients and the association with radiological measurements, clinician and patient-reported outcomes. Arch Orthop Trauma Surg,2018;138:16991712, doi:10.1007/s0040 2-018-3046-2

[6] Quadlbauer S, Pezzei Ch, J. Jurkowitsch J, Rosenauer R, Kolmayr B, Keuchel T, Simon D, Beer T, Hausner T, Leixnering M. Rehabilitation after distal radius fractures: is there a need for immobilization and physiotherapy? Arch. Orthop Trauma Surg. 2020; 140(5):651-663, doi: 10.1007/s00402-020-03367-w.

[7] Lee DY, Park YJ, Park JS.A meta-analysis of studies of volar locking plate fixation of distal radius fractures: Convectional versus minimally invasive plate osteosynthesis. Clin Orthop Surg, 2019;11(2):208-219, doi:10.4055/cios.2019. 11. 2. 208.

[8] Lafontaine M, Hardy D, Delince P. Stability assessment of distal radius fractures. Injury 1989;20(4):208-210, doi:10.1016/0020-1383(89)90113-7.
[9] Gook CJC, Bindra RR, Tarrant DJ, Thomas JE. Volar locking plate fixation of distal radius fractures: a metaanalysis. J. Hand Surg(Eur),2018;43(9):954-960, doi:10.1177/1753193417743938

[10] Fu YC, Chien SH, Huang PJ, Chen SK, Tien YC, Lin GT, Wang GJ. Use of an external fixaרtion combined with the buttress-maintain pinning method in treating comminuted distal radius fractures in osteopo $\neg$ rotic patients. J Trauma. 2006;60(2):330-3, doi;10.1097/01.ta.0000203538.29179.5b.

[11] Chung KC, Squitieri L, Kim HM. Comparative outcomes study using the volar locking plating system for distal radius fractures in both young adults and adults older than 60 years. J Hand Surg Am. 2008;33(6):809-19, doi:10.1016/j.jhsa.2008.02.016.

[12] McKay SD, Mac Dermid JC, Roth JH. Richards RS. Assessment of complications of distal radius fractures and development of a complication checklist. J Hand Surg Am. 2001; 26(5):916-22, doi:10.1053/jhsu.2001.26662.

[13] Thorninger R, Madsen ML, Wæver D, Borris LC, Rölfing JHD. Complications of volar locking plating of distal radius fractures in 576 patients with 3.2 years follow-up. Injury 2017; 48(6):1104-1109, doi:10.1016/j.injury.2017.03.008.

[14] Li Y, Zhou Y, Zhang X, Tian D, Zhang B. Incidence of complications and secondary procedure following distal radius fracture treated by volar locking plate. J Orthop Surg Res. 2019;14(1):295, doi;10.1186/s13018-0191344-1.

[15] Tubeuf S, Yu G, Achten J, Parson NR, Rangan A, Lamb SE, Costa ML. Cost effectiveness of treatment with percutaneous Kirschner wires versus volar locking plate for adult patients with a dorsally displaced fracture of the distal radius: analysis from the DRAFFT trial. Bone Joint J. 2015;97-b(8):1082-9, doi:10.1302/030162ox.97b8.35234.

[16] Orbay JL, Badia A, Indriago IR, Infante A, Khouri RK, Gonzalez E, Fernandez DL. The extended flexor carpi radialis approach; a new perspective for the distal radius fracture. Tech Hand Up Extrem Surg. 2001; 5(4):204211, doi: 10.1097/00130911-200112000-00004.

[17] Soong M, Earp BE, Bishop G, Leung A, Blazar P. Volar locking plate implant prominence and flexor tendon rupture. J Bone Joint Surg Am. 2011;93(4):328-335, doi:10.2106/JBJS.J.00193.

[18] Kastanis G, Pantouvaki A, Magarakis G, Chaniotakis C, Christoforidis C, Kapsetakis P. Simultaneous distal radius fracture with acute radial artery injury: is it a unique complex injury or a misdiagnosis lesion. International Journal of Innovative Research in Medical Science. 2021;06(2):143-148, doi:10.23958/ijirms/vol06i02/1059.

[19] O'Neill TW, Cooper c, Finn JD, Lunt M, Purdie D, Reid $\mathrm{DM}$, Rowe R, Woolf $\mathrm{AD}$, Wallace WA. Incidence of distal forearm fracture in British men and women. Osteoporos Int 2001;12(7):555-8, doi:10.1007/s0011980170076.

[20] Weil NL, El Moumni M, Rubinstein SM, Krijnen P, Termaat MF, Schipper IB, Routine follow-up radiographs for distal radius fractures are seldom clinically substantiated. Arch Orthop Trauma Surg. 
2017;137(9):1187-1191, doi.org /10.1007/ s0040 2-0172743-6.

[21] Orbay JL, Fernandez DL. Volar fixation for dorsally displacement fractures of the distal radius: a preliminary report. J Hand Surg AM.2002;27(2):205-215, doi:10.1053/jhsu.2002.32081.

[22] Trease C, McIff T, Toby EB. Locking versus nonlocking T-plates for dorsal and volar fixation of dorsally comminuted distal radius fractures: a biomechanical study. J Hand Surg Am. 2005; 30(4):756-763, doi:10.1016/j.jhsa.200504.017.

[23] Wilson J, Viner JJ, Johal KS, Woodruff MJ. Volar locking plate fixation for displaced distal radius fractures: An evaluation of complication and radiographic outcomes. Hand(NY). 2018;13(4):466-472, doi: $10.1177 / 1558944717717505$.

[24] Alter TH, Sandrowski K, Gallant G, Kwok M, Ilyas AM. (2019) Complications of volar plating of distal radius fractures: a systematic review. J Wrist Surg 2019;8(3):255-262, doi:10.1055/s-0038-1667304.

[25] Quadlbauer S, Pezzei C, Jurkowitsch J, Rosenauer R, Pichler A, Schättin S, Hausner T, Leixnering $M$. Functional and radiological outcomes of distal radius fractures stabilized by volar locking plate with a minimum follow-up of 1 year. Arch Orthop Trauma Surg.2020;140(6):843-852, doi:10.1007/s00402-02003411-9.

[26] Rosenauer R, Pezzei C, Quadlbauer S, Keuchel T, Jurkowitsch J, Hausner T, Leixnering M. Complications after operatively treated distal radius fractures. Arch Orthop Trauma Surg. 2020;140(5):665-673, doi:10.1007/s0040 2-020-03372-Z

[27] Bentohami A, de Burlet K, de Korte N, van den Bekerom MP, Goslings JC, Schep NW. Complications following volar locking plate fixation for distal radial fractures: A systematic review. J Hand Surg Eur Vol. 2014;39(7):745-754, doi:10.1177/1758193413511936.

[28] De George BR, Brogan DM, Becker HA, Shun AY. Incidence of complications following volar locking plate fixation of distal radius fractures: an analysis of 647 cases. Plast Reconstr Surg 2020;14(5):969-976, doi:10.1097/prs.0000000000006636.

[29] Esenwein P, Sonderegger J, Gruenert J, Ellenrieder B, Tawfik J, Jakubietz M. Complications following palmar plate fixation of distal radius fractures: a review of 665 cases. Arch Orthop Trauma Surg 2013;133(8):11551162, doi:10.1007/s00402-013-1766-x

[30] Disseldorp DJG, Hannemann PFW, Poeze M, Brink RPG. Dorsal or volar plate fixation of the distal radius: Does the complication rate help us to choose? J Wrist Surg 2016;5(3):202-210, doi:10.1055/s-0036-1571842.

[31] Rampoldi M, Marsico S. Complications of volar plating of distal radius fractures. Acta Orthop Belg. 2007; 73(6):714-719.

[32] Arora R, Lutz M, Hennerbichler A, Krappinger D, Espen D, Gabl M. Complications following internal fixation of unstable distal radius fracture with a palmar lockingplate. J Orthop Trauma. 2007;21(5):316-322, doi:10.1097/BOT.0b013e318059b993.
[33] Cross AW, Schmidt CC. Flexor tendon injuries following locked volar plating of distal radius fractures. J Hand Surg Am. 2008;33(2):164-167, doi:10.1016/j.jhsa.2007.11.011.

[34] Imatani J, Akita K, Yamaguchi K, Shimizu H, Kondou $\mathrm{H}$, Ozaki T. An anatomical study of the watershed line on the volar, distal aspect of the radius: implications for plate placement and avoidance of tendon ruptures. J Hand Surg Am. 2012;37(8):1550-1554, doi:10.1016/j.jhsa.2012.05.011.

[35] Tanl ECT, Janssen AJM, Roestenbergl P, van den Heuvel LP, Goris JA, Rodengurg RJT. Mitochondrial dysfunction in muscle tissue of complex regional pain syndrome type I patients. Eur J Pain. 2011; 15(7):708715. doi:10.1016/j.ejpai n.2010.12.003

[36] Roh YH, Lee BK, Noh JH Baek JR, Oh JH, Gong HS, Baek GH. Factors associated with complex regional pain syndrome type I in patients with surgically treated distal radius fracture. Arch Orthop Trauma Surg. 2014; 134(12):1775-1781. doi:10.1007/s0040 2-014-2094-5.

[37] Buzzell JE, Weikert DR, Watson JT, Lee DH. Precontoured fixed-angle volar distal radius plates: a comparison of anatomic fit. J Hand Surg Am. 2008;33(7):1144-1152, doi:10.1016/j.jhsa.2008.02.029.

[38] Drobetz H, Bryant AL, Pokorny T, Spitaler R, Leixnering M, Jupiter JB. Volar fixed-angle plating of distal radius extension fractures: influence of plate position on secondary loss of reduction - a biomechanic study in a cadaveric model. $\mathbf{J}$ Hand Surg Am. 2006;31(4):615-622, doi:10.1016/j.jhsa.2006.01.011.

[39] Sirnio K, Flinkkilä T, Vähäkuopus M, Hurskainen A, Ohtonen P, Leppilahti J. Risk factors for complications after volar plate fixation of distal radial fractures. J Hand Surg Eur. 2019;44(5):456-461, doi: $10.11177 / 1753193418811559$.

[40] Glueck DA, Charoglu CP, Lawton JN. Factors associated with infection following open distal radius fractures. Hand. 2009;4(3):330-4, doi:10.1007/s11552-009-9173-z.

[41] Tsang KH, Choi KY, Chan YF, Lau SC, Chow YY. Locking plate for $\mathrm{AO}$ type $\mathrm{C}$ intraarticular distal radius fracture: Volar or dorsal approach. J of Orthop Trauma \& Rehab. 2014; 18:83-88, doi:10.1016/j.jotr.2013.09.003.

[42] Benson LS, Minihane KP, Stern LD, Eller E, Seshadri R. The outcome of intra-articular distal radius fractures treated with fragment-specific fixation. J Hand Surg Am. 2006;31(8):1333-9, doi:10.1016/j.jhsa.2006.07.004.

[43] Lee HC, Wing YS, Chan BK, Low CO. Fixation of distal radius fractures using $\mathrm{AO}$ titanium volar distal radius plate. Hand Surg. 2003;8(1):7-15, doi:10.1142/s0218810403001339.

[44] Harness NG, Jupiter JB, Orbay JL, Raskin KB, Fernadez DL. Loss of fixation of the volar lunate facet fragment in fractures of the distal part of the radius. J Bone Joint Surg Am Vol. 2004; 86(9):1900-8, doi: 10.2106/00004623-200409000-00007.

[45] Berglund LM, Messer TM. Complications of volar plate fixation for managing distal radius fractures. J Am Acad Orthop Surg. 2009;17(6):369-77, doi:10.5435/00124635 $-200906000-00005$. 